\title{
$r$
}

\section{REVIEW OF REMOTE SENSING TECHNOLOGIES AND DATA FOR DOE-EM APPLICATIONS}

\author{
Principal Investigator:
}

M.A. Ebadian, Ph.D.

Florida International University

Collaborator:

Lillybet Ledo

Prepared for:

U.S. Department of Energy Office of Environmental Management Office of Science and Technology

Hemispheric Center for Environaental Technoloct (hCET) Florida International University, Center for Engineering \& Applied Sciences 10555 West Flagler Street, EAS-2100, Miami, Florida 33174

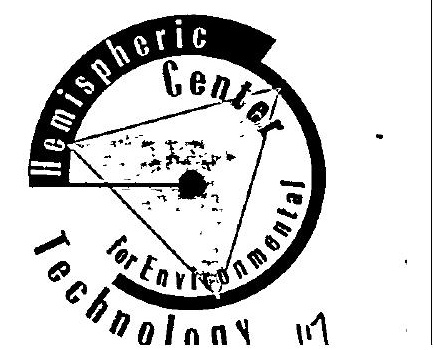




\section{DISCLAIMER}

This report was prepared as an account of work sponsored by an agency of the United States government. Neither the United States government nor any agency thereof, nor any of their employees, nor any of its contractors, subcontractors, nor their employees makes any warranty, express or implied, or assumes any legal liability or responsibility for the accuracy, completeness, or usefulness of any information, apparatus, product, or process disclosed, or represents that its use would not infringe upon privately owned rights. Reference herein to any specific commercial product, process, or service by trade name, trademark, manufacturer, or otherwise does not necessarily constitute or imply its endorsement, recommendation, or favoring by the United States government or any other agency thereof. The views and opinions of authors expressed herein do not necessarily state or reflect those of the United States government or any agency thereof. 


\section{DISCLAIMER}

\section{Portions of this document may be illegible in electronic image products. Images are produced from the best available original document.}




\title{
REVIEW OF REMOTE SENSING TECHNOLOGIES AND DATA FOR DOE-EM APPLICATIONS \\ M.A. Ebadian, Ph.D. \\ Hemispheric Center for Environmental Technology \\ Florida International University \\ Miami, FL 33174
}

\section{Florida International University Collaborator}

\author{
Lillybet Ledo \\ Hemispheric Center for Environmental Technology \\ Florida International University \\ Miami, FL 33174
}

January 1999

Prepared for

U.S. Department of Energy

Office of Environmental Management

Office of Science and Technology

Under Grant No.: DE-FG21-95EW55094 


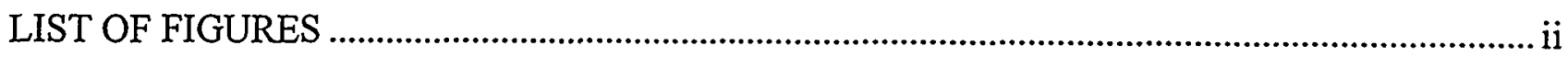

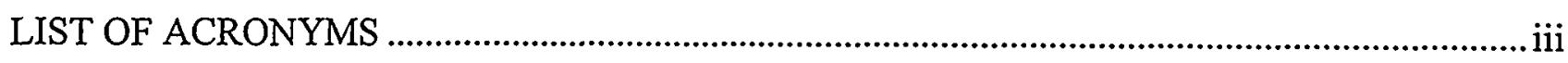

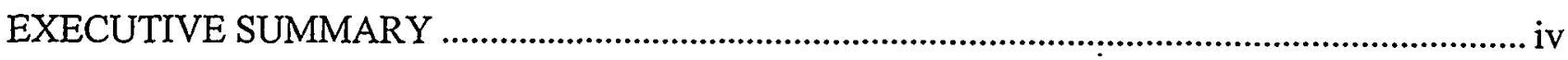

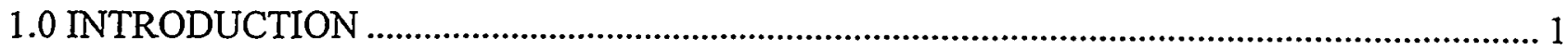

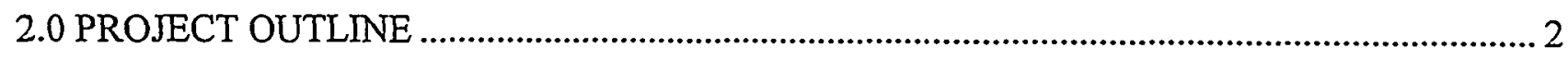

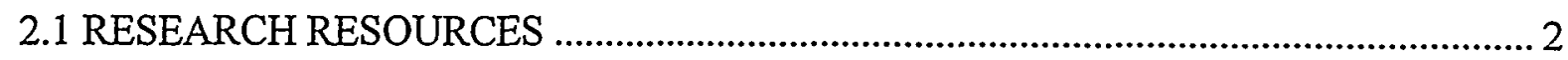

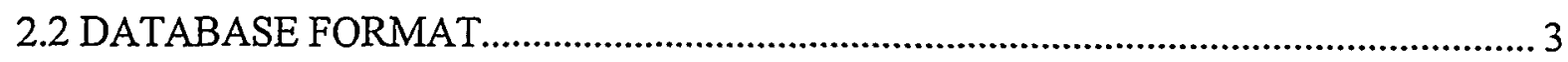

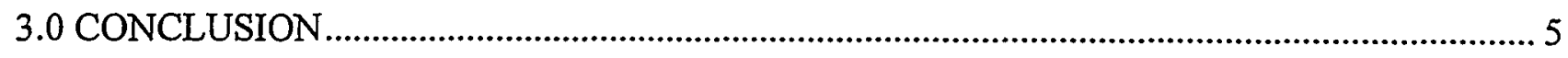

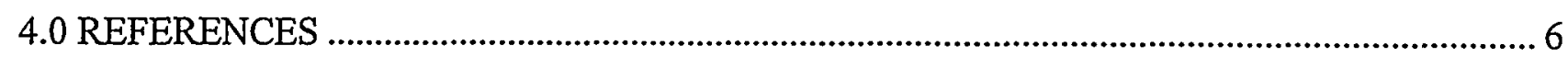




\section{LIST OF FIGURES}

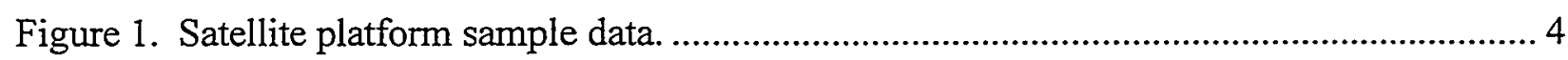

Figure 2. Airborne platform sample data......................................................................... 4 


\section{LIST OF ACRONYMS}

DOD Department of Defense

DOE Department of Energy

EM Environmental Management

NASA National Aeronautics and Space Agency

NASDA National Space Development Agency of Japan

VNIR Very Near Infrared Band

SWIR Short-Wave Infrared Band

M/TIR Medium/Thermal Infrared band 


\section{EXECUTIVE SUMMARY}

This subtask began in November 1996 (FY97) and continued through FY98. The project's aim was to assist in deploying Laser-Induced Fluorescence Imaging (LIFI) technology to the agricultural private sector, especially to countries in Latin America and the Caribbean. To accomplish this, a survey was conducted to identify agricultural community needs and the current remote sensing activities that could favor deploying LIFI technology. A market survey was conducted to identify the principal crops and livestock raised in countries in the Western Hemisphere and to rank the countries based on financial resources, production and export quantities, and market share. Argentina, Brazil, Chile, Mexico, and Colombia were identified as the most significant markets in the region and the countries that could benefit from sensor technologies developed by the Department of Energy's Office of Science and Technology (DOEOST).

Due to circumstances beyond FIU-HCET's control, the scope of this project was redirected in April 1998 and a new focus, "Review of Remote Sensing Technologies and Data for DOE-EM Applications" was defined for the remainder of FY98. Currently, DOE is working on many projects dealing with remote sensing activities in the environmental field. The new subtask inventoried remote sensing technologies and data that are currently available or in an advanced research state. It identified ones applicable to DOE-EM's needs. This activity revealed that there are many entities, including NASA and DOE's Office of Arms Control, that are researching new technologies and are collecting and analyzing remote sensing data. There are many technologies commercially available for different applications, including environmental and agricultural.

FIU-HCET personnel researched the remote sensing technologies and contacted several individuals involved in remote sensing activities to assist in identifying the most appropriate and useful information. When the information was gathered, a database was created, consisting of different sensor platforms (satellite and airborne). For the satellite platform, the database contains a list of all of the satellites along with all of the sensors on board the satellite. It contains the specifications for the satellites and sensors (e.g., sensor type, inclination, period, resolution, and swath width). The section on the airborne platform contains a list of the sensors carried on the different aircraft, along with the specifications (e.g., bandwidth, field of view, and image acquisition mode). This database will greatly ease the work for people searching for information on this subject; in turn, this will save DOE researchers/employees an inordinate amount of time. 


\subsection{INTRODUCTION}

Various governmental agencies and private companies throughout the world are involved in remote sensing activities. Remote sensing is a technology used for the purpose of monitoring the earth's environment, keeping track of the earth's resources, and for agricultural vegetation monitoring, among other things. There is a vast number of remote sensing technologies and data already commercially available for different applications (e.g., environmental, agricultural, and so on). Many entities are actively conducting research to generate new technologies and data (e.g., NASA). In addition, some of DOE's offices and programs, such as the Office of Arms Control, have engaged in collection and analysis of remote sensing data. It is likely that some of these technologies and data could be useful for characterization and monitoring of EM's sites.

Florida International University's Hemispheric Center for Environmental Technology (FIUHCET) has reviewed remote sensing technologies and data that are currently available or in an advanced research state. The review focused on the technologies and data applicable to the environmental field. DOE has over 800 national laboratories and sites dispersed throughout the United States. involved in some current and past remote sensing projects. FIU-HCET personnel have searched governmental agency databases (e.g., DOE, NASA), the Internet, and library resources to obtain information about these technologies and generated a user-friendly database.

This review has also produced an inventory and will be available on the Internet and on a CDROM that can be distributed to individuals or entities requesting information on remote sensing technologies and data for environmental applications. This database contains information regarding each technology, such as type of sensor, applications, and technical specifications (e.g., resolution). To the best of FIU-HCET's knowledge, a database of this type and with this level of detail does not exist within DOE.

With the amount of remote sensing data collected around the country, this project will help in the exchange of information from one DOE site to another. If someone needs to find information about any remote sensing technology today, the person must do Internet research for a lengthy period of time before they come across what they might be looking for. Even then there is no guarantee the information sought after will be found on the Internet, giving the researcher no choice but to continue wasting valuable time by searching through the library and other resources. This database will make it easier to do any research performed by employees of DOE, saving them both time and money. 


\subsection{PROJECT OUTLINE}

Remote sensing is a technology used for the purpose of monitoring the earth's environment, keeping track of the earth's resources, and for agricultural vegetation monitoring, among other things. It uses a multisensor system strapped on to the wings of an airplane reaching heights of tens of thousands of feet. Remote sensing techniques such as aerial photographs, multispectral scanning, and airborne geophysical systems are of unquestioned value for hazardous waste site characterization. However, remote sensing is expensive and is usually flown over large areas, thus reducing the cost per square mile of surface scanned. The high cost has been due to the size of the equipment needed to accomplish the operation; however, with the development of lightweight, compact instrumentation, it no longer requires large aircraft. Small remotecontrolled aircraft can now do the overflights and obviously can be used successfully over very small sites for a much lower fee.

This project involved enormous amounts of research. The research was accomplished via the Internet, the library, magazines, phone calls to DOE sites, and so forth.

\subsection{RESEARCH RESOURCES}

To find the appropriate information, FIU-HCET personnel:

- researched the Internet using several search engines

- researched Florida International University's library for data

- searched several DOE and DOD websites

- searched several NASA websites that provided vast information on remote sensing technologies

- contacted several individuals from different agencies that own satellites and aircraft (e.g., NASA GSFC, about the TRMM satellite) to help provide information on the platform and sensors.

The internet was used as one of the sources to find different technologies and corresponding information. Searches were conducted using several keywords (e.g., remote sensors, hyperspectral sensor, and multispectral scanners) that generated several website addresses. These were perused, and any appropriate information found was then thoroughly examined and added to the database.

A very useful website was "The Satellite Encyclopedia" (http://www.tbs-satellite.com/tse). This site listed information about all satellites that are currently in orbit as well as ones that are no longer operational. It also contained information on all the sensors aboard each satellite and provided links to other sites for more information. It was found that NASA is very actively involved in remote sensing activities through varied space missions. Several NASA websites (http://www.nasa.gov) provided very useful information. NASA also has its own remote sensing technology, the Tropical Rainfall Measuring Mission (TRMM). 
Hundreds of websites were searched, but only a few provided vast amounts of information. One of these sites was "Resources in Earth Observation - Instrument Catalogue" (http://wwwprojet.cst.cnes.fr/ceos/cdrom/ceos1). This site listed all remote sensors aboard satellites along with applications and other characteristics. Another useful site was "Satellite Remote Sensing Services" (http://www.rss.dola.was.gov.au/sat_info). This site listed the satellite platforms and its sensors characteristics. It also listed which satellites were in orbit, which were no longer operating, and which would be launched in the near future. This website, http://www.ba.dlr.de/NE-WS/ws5/sensor/, listed some remote sensors for both satellite and aircraft platforms. It contained information about the characteristics of each sensor and the companies or agencies operating them. A list of airborne remote sensors and their characteristics was found in the website titled, "Imaging Spectrometers" (http://www.geo.unizh.ch/ schaep/ research/apex/is_list.html).

Another source used to find data was Florida International University's library. Several journals were found that contained information needed. If the journal was not found in this library, it was ordered through Interlibrary Loans. The article entitled, "The Tropical Rainfall Measuring Mission (TRMM) Sensor Package" from the Journal of Atmospheric and Oceanic Technology provided all the information about the TRMM satellite and its sensors. It contained applications, specifications and characteristics of the TRMM. Another journal used was the December 1997 edition of Geocarto International: A Multi-disciplinary Journal of Remote Sensing \& GIS. This journal provided essential information about NASDA and its sensors. This edition listed NASDA's sensors as well as specifications, characteristics, and comparisons to other satellites.

\subsection{DATABASE FORMAT}

For the format of the database, several individuals from commercial companies involved in remote sensing activities were contacted and asked to advise FIU-HCET personnel on best format for the database and to assist in identifying most appropriate and useful parameters to be included in the database. Many of them kindly listed the information that they use on their work as well as those parameters they would like to have readily available, which are not. Then, the database was formatted to include their advice and suggestions. These individuals provided very useful information, and the database is also tailored to fulfill their needs. The database has two different sections according to the sensor platform: satellite or airborne.

For the satellite platform, the database contains a list of all the satellites along with all the sensors aboard each satellite. It contains the technical specifications for the satellites (e.g., inclination, perigee, and apogee) and for the sensors (e.g., sensor type, inclination, period, resolution, and swath width). This section also contains each sensor's applications (what the sensor does and what it is used for), which enhances the search capabilities because it enables the user to search for the sensor that will generate the data required. Figure 1 depicts a sample of the database content for the satellite platform.

For the airborne platform, the database contains a list of the different sensors carried on aircraft, along with the technical specifications (e.g., field of view, bandwidth, and image acquisition mode). This section also lists each sensor's applications (what the sensor does and what it is used for), which enhances the search capabilities because it enables the user to search for the sensor that will generate the data required. Figure 2 depicts a sample of the database content for the airborne platform. 


\begin{tabular}{|l|l|l|l|l|l|l|}
\hline Satellite Name & Status:" & Inclination & Equatorial Crossing & Perigee & Apoged & Périod (min) \\
\hline JERS - 1 & Operational & 98 & $10: 30-11: 00$ & $558 \mathrm{~km}$ & $579.9 \mathrm{~km}$ & 96
\end{tabular}

\begin{tabular}{|c|c|c|c|c|c|c|c|c|c|c|}
\hline Sensor & Type & Channels & Resolution & Frequency & Polarization & Angle & Bandwidth & Pixel & Swath & Data \\
\hline SAR & Radar & 1 & $18 \times 18$ & $\begin{array}{l}1275 \mathrm{MHz} \\
\text { (L-band) }\end{array}$ & HH & $37-43$ & $15 \mathrm{MHz}$ & & $75 \mathrm{~km}$ & $\begin{array}{l}\text { High resolution } \\
\text { monitoring of land } \\
\text { use and type, glacier } \\
\text { extent, snow cover, } \\
\text { surface topography, } \\
\text { ocean currents and } \\
\text { waves. }\end{array}$ \\
\hline
\end{tabular}

Figure 1. Satellite platform sample data.

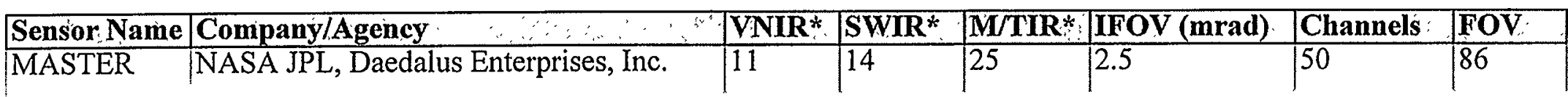

\begin{tabular}{|l|l|l|l|l|l|}
\hline Bandwidth & Image & Spectral & Aircraft & & Application \\
\hline $40-700$ & Whiskbroom & grating, filter & NASA ER-2, DC-8 & Study of geologic and other Earth surface properties. \\
\hline
\end{tabular}

Figure 2. Airborne platform sample data.

Unfortunately, all the information needed to complete the database was not readily available. Therefore, many individuals from different agencies involved in remote sensing activities were contacted. Some individuals pointed out several articles in journals that would contain information; others mailed the information either by postal service or electronically. For example, NASA provided insight information on the TRMM. They provided the name of an article containing the information needed. FIU-HCET personnel looked it up at Florida International University's library. The library did not have the article, but it was ordered through FIU's Interlibrary Loans department from another state university. NASDA provided booklets containing information about its satellites and sensors. 


\subsection{CONCLUSION}

The database currently contains 110 remote sensors. Of these 110 sensors, 68 are satellite-based, and the other 42 are airborne. This review focused on the remote sensing technologies and data applicable to the environmental field and an inventory of those technologies was produced in a database format. The database will be available on the Internet and on a CD-ROM. This inventory can be distributed to individuals or entities within DOE or others requesting information on remote sensing technologies and data for environmental purposes. To the best of FIU-HCET's knowledge, a database of this type and with this level of detail does not exist within DOE. 


\subsection{REFERENCES}

Geocarto International: A Multi-disciplinary Journal of Remote Sensing \& GIS, December 1997, Vol. 12, No. 4.

Kummerow, C. and Barnes, W., "The Tropical Rainfall Measuring Mission (TRMM)," Journal of Atmospheric and Oceanic Technology, June 1998, Vol. 15, No. 3, pp. 809-817. 